\title{
An optimal nonlinear control for anti-synchronization of Rabinovich hyperchaotic system
}

\author{
Shaymaa Y. Al-hayali, Saad Fawzi AL-Azzawi \\ Department of Mathematics, College of Computer Sciences and Mathematics, University of Mosul, Iraq
}

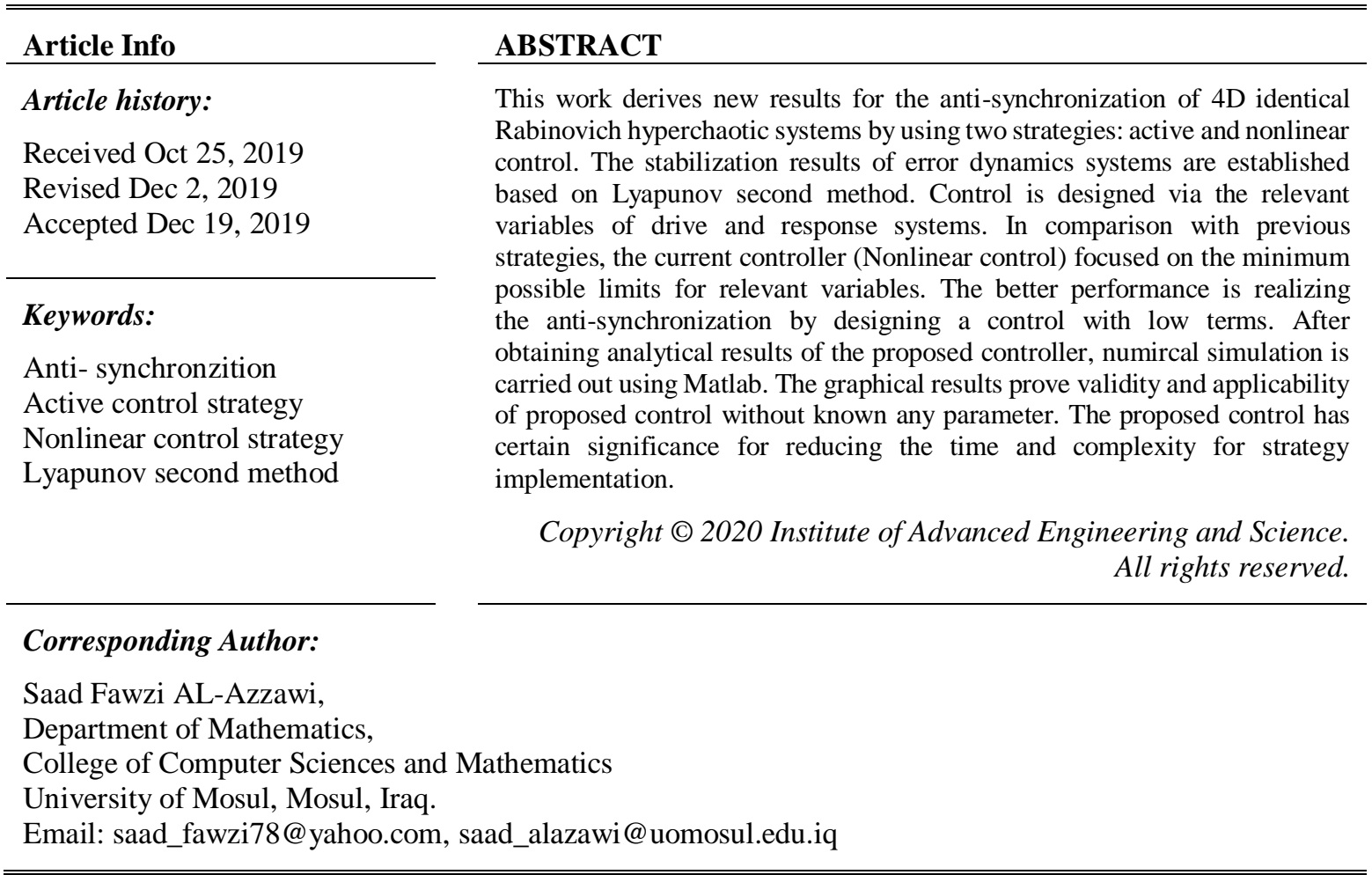

\section{INTRODUCTION}

The impetus for advances in dynamical systems has come from many sources: mathematics, theoretical science, computer simulation, and experimental science. The key requirement for these systems involves a nonlinearity. In 1990, Pecora and Carroll brought to the world the idea of synchronization of dynamical systems $[1,2]$. Chaos synchronization has attracted considerable attention due to its important applications in physical systems [3], Encryption [4, 5], and secure communications [6], etc. This greatest success opened the way to discover another phenomenon.

Until now, scientists realize that chaos synchronization can be observed in experiments and in computer models of behavior from all fields of science and engineering [7]. In addition, enormous synchronization phenomena have been applied in various dynamical systems such as complete synchronization (CS) [8-11], anti-synchronization(AS) [12], Hybrid Synchronization (HS) [13], projective synchronization (PS) [14], modified projective synchronization (MPS) [15] and generalized projective synchronization (GPS) [16]. Full synchronization and anti-synchronization are the most commonly used [17] and play an important role in engineering applications [18, 19].

These phenomena are achieved via different various types of anti-synchronization schemes including active control [17], adaptive control, nonlinear control [18-21] and linear feedback control [22-24]. Among the aforementioned schemes, active control and nonlinear control have been widely used as two powerful strategies for the anti-synchronization of different classes of nonlinear dynamical systems [16-20]. The nonlinear control strategy is considered as one of the powerful tools for controlling the dynamical systems. However, the active control suffers from many terms corresponding to relevant variables of drive and response systems. To overcome this problem, the nonlinear control strategy is used with the minimum of terms 
anti-synchronization whereas nonlinear control strategy has demonstrated excellent performance in anti-synchronization schemes.

In this paper, we implement anti-synchronization between two 4D identical Rabinovich hyperchaotic systems based on active and nonlinear control strategies via Lyapunov second method and observed that the number of terms less than the first strategy. The proposed control with low terms is more interesting and easily applied and implemented.

Major contributions of this work are as follows: (i) active and nonlinear control strategy based Lyapunov second method is utilized for anti-synchronization. (ii) Proposed controllers are exploited without known any parameter. (iii) A necessary and sufficient condition is proposed to show how many relevant variables of drive and response systems can achieve an anti-synchronization underactive and nonlinear controller. (iv) After deriving analytical results, numerical simulation is carried out using Matlab. (v) The validity and applicability of the proposed controllers are proven with graphical results.

The rest of this paper is organized as follows. Section 2 is the description of the hyperchaotic Rabinovich System. Section 3 presents the problem of anti-synchronization for the hyperchaotic Rabinovich. Section 4 is the conclusions of this paper.

\section{DECRIPTION OFHYPERCHAOTIC RABINOVICH SYSTEM}

Rabinovich system is a four-dimensional hyperchaotic which include ten terms, three of them are nonlinearity with three parameters and descript by the following form $[25,26]$ :

$$
\left\{\begin{array}{l}
\dot{x}_{1}=-a x_{1}+h x_{2}+x_{2} x_{3} \\
\dot{x}_{2}=h x_{1}-x_{2}-x_{1} x_{3}+x_{4} \\
\dot{x}_{3}=-x_{3}+x_{1} x_{2} \\
\dot{x}_{4}=-k x_{2}
\end{array}\right.
$$

where $x_{1}, x_{2}, x_{3}, x_{4}$ are the state variables and $a=4, h=6.75, k=2$ are positive constants. Figures $1-2$ show the attractor of system (1):

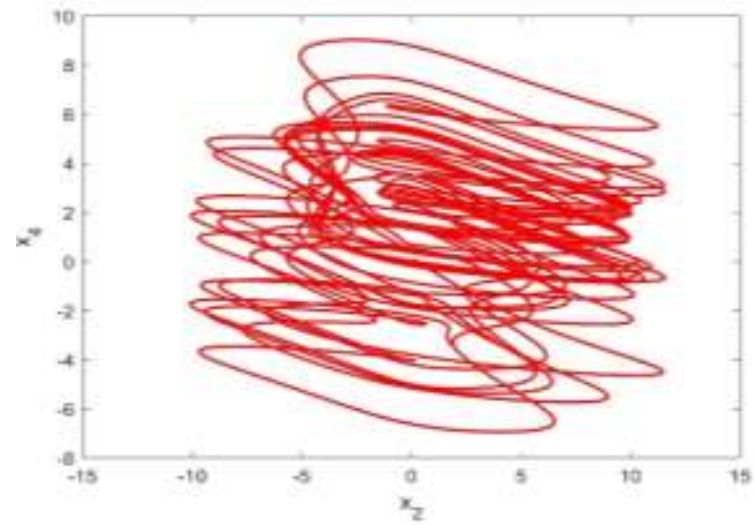

Figure 1. The attractor of system (1) in $x_{2}-x_{4}$ plane

\section{ANTI-SYNCHRONIZATION RABINOVICH SYSTEM}

In order to achieve anti-synchronization for the Rabinovich system, two systems are needed, the first system (1) is called the drive system, and the second system is called the response system. The response system for the Rabinovich system depicts in (2).

$$
\left\{\begin{array}{l}
\dot{y}_{1}=-a y_{1}+h y_{2}+y_{2} y_{3}+u_{1} \\
\dot{y}_{2}=h y_{1}-y_{2}-y_{1} y_{3}+y_{4}+u_{2} \\
\dot{y}_{3}=-y_{3}+y_{1} y_{2}+u_{3} \\
\dot{y}_{4}=-k y_{2}+u_{4}
\end{array}\right.
$$


where $u=\left[u_{1}, u_{2}, u_{3}, u_{4}\right]^{T}$ is the controller to be designed, the anti-synchronization error $e \in R^{4}$ is defined as :

$e_{1}=y_{1}-\alpha_{i} x_{1}, e_{2}=y_{2}-\alpha_{i} x_{2}, e_{3}=y_{3}-\alpha_{i} x_{3}, e_{4}=y_{4}-\alpha_{i} x_{4}, \forall \alpha_{i}=-1, \forall \alpha_{i}=-1, i=1,2,3,4$ So, the error dynamical system is given by:

$$
\left\{\begin{array}{l}
\dot{e}_{1}=-a e_{1}+h e_{2}+e_{2} e_{3}-x_{3} e_{2}-x_{2} e_{3}+2 x_{2} x_{3}+u_{1} \\
\dot{e}_{2}=h e_{1}-e_{2}+e_{4}-y_{1} e_{3}-x_{3} e_{1}+2 y_{1} x_{3}+u_{2} \\
\dot{e}_{3}=-e_{3}+e_{1} e_{2}-x_{2} e_{1}-x_{1} e_{2}+2 x_{1} x_{2}+u_{3} \\
\dot{e}_{4}=-k e_{2}+u_{4}
\end{array}\right.
$$

\subsection{Anti-synchronization based on active control}

To realize the anti-synchronization, we need to design suitable nonlinear control. Therefore, the control functions are chosen as the following:

$$
\left\{\begin{array}{l}
u_{1}=-e_{2} e_{3}+x_{3} e_{2}+x_{2} e_{3}-2 x_{2} x_{3}+v_{1} \\
u_{2}=y_{1} e_{3}+x_{3} e_{1}-2 y_{1} x_{3}+v_{2} \\
u_{3}=-e_{1} e_{2}+x_{2} e_{1}+x_{1} e_{2}-2 x_{1} x_{2}+v_{3} \\
u_{4}=v_{4}
\end{array}\right.
$$

inserting the control (4) in (3) we get:

$$
\left\{\begin{array}{l}
\dot{e}_{1}=-a e_{1}+h e_{2}+v_{1} \\
\dot{e}_{2}=h e_{1}-e_{2}+e_{4}+v_{2} \\
\dot{e}_{3}=-e_{3}+v_{3} \\
\dot{e}_{4}=-k e_{2}+v_{4}
\end{array}\right.
$$

where $v$ is linear control, $A$ is a constant matrix. To make the system (5) stable, the matrix $A$ should be selected by the following:

$$
A=\left[\begin{array}{cccr}
(a-1) & -h & 0 & 0 \\
-h & (1-2 a) & 0 & -1 \\
0 & 0 & -2 & 0 \\
0 & k & 0 & -k
\end{array}\right]
$$

hence, the error dynamical system (3) with above matrix becomes:

$$
\left\{\begin{array}{l}
\dot{e}_{1}=-e_{1} \\
\dot{e}_{2}=-2 a e_{2} \\
\dot{e}_{3}=-3 e_{3} \\
\dot{e}_{4}=-k e_{4}
\end{array}\right.
$$

therefore, the above system has all eigenvalues with negative real parts. These eigenvalues guarantee the stability of the system (7). So, the response system (2) is anti-synchronization with the drive system. Hence, we reach the following results.

Theorem 1: If the matrix (6) is combined with the system (5), then, the response system (2) unfollows the drive system (1) via the following nonlinear active control which consists of (21) terms.

$$
\left\{\begin{array}{l}
u_{1}=(\mathrm{a}-1) e_{1}-h e_{2}-e_{2} e_{3}+x_{3} e_{2}+x_{2} e_{3}-2 x_{2} x_{3} \\
u_{2}=-h e_{1}+(1-2 \mathrm{a}) e_{2}-e_{4}+y_{1} e_{3}+x_{3} e_{1}-2 y_{1} x_{3} \\
u_{3}=-2 e_{3}-e_{1} e_{2}+x_{2} e_{1}+x_{1} e_{2}-2 x_{1} x_{2} \\
u_{4}=k e_{2}-k e_{4}
\end{array}\right.
$$

Proof: Based on the Lyapunov second method, we construct a positive definite Lyapunov candidate function as:

$$
\mathrm{V}(\mathrm{e})=e^{T} p e=\frac{1}{2} e_{1}^{2}+\frac{1}{2} e_{2}^{2}+\frac{1}{2} e_{3}^{2}+\frac{1}{2} e_{4}^{2}
$$


where $P=\operatorname{diag}\left[\frac{1}{2}, \frac{1}{2}, \frac{1}{2}, \frac{1}{2}\right]$, the derivative of the Lyapunov function $\mathrm{V}(\mathrm{e})$ with respect to time is:

$$
\begin{aligned}
& \dot{V}(e)=e_{1} \dot{e}_{1}+e_{2} \dot{e}_{2}+e_{3} \dot{e}_{3}+e_{4} \dot{e}_{4} \\
& \dot{V}(e)=e_{1}\left(-e_{1}\right)+e_{2}\left(-2 a e_{2}\right)+e_{3}\left(-3 e_{3}\right)+e_{4}\left(-k e_{4}\right) \\
& \dot{V}(e)=-e_{1}^{2}-2 a e_{2}^{2}-3 e_{3}^{2}-k e_{4}^{2}=-e^{T} Q e, Q=\operatorname{diag}[1,2 a, 3, k]
\end{aligned}
$$

Every diagonal matrix with positive diagonal elements is positive definite. So $Q>0$. Therefore, $\dot{V}(e)$ is negative definite. And according to the Lyapunov asymptotical stability theory, the nonlinear active controller is implemented and the anti-synchronization of the hyperchaotic system is achieved. The proof is now complete. The theorem 1 shows that proposed control which consists of (21) terms achieved anti-synchronization in Figure 3.
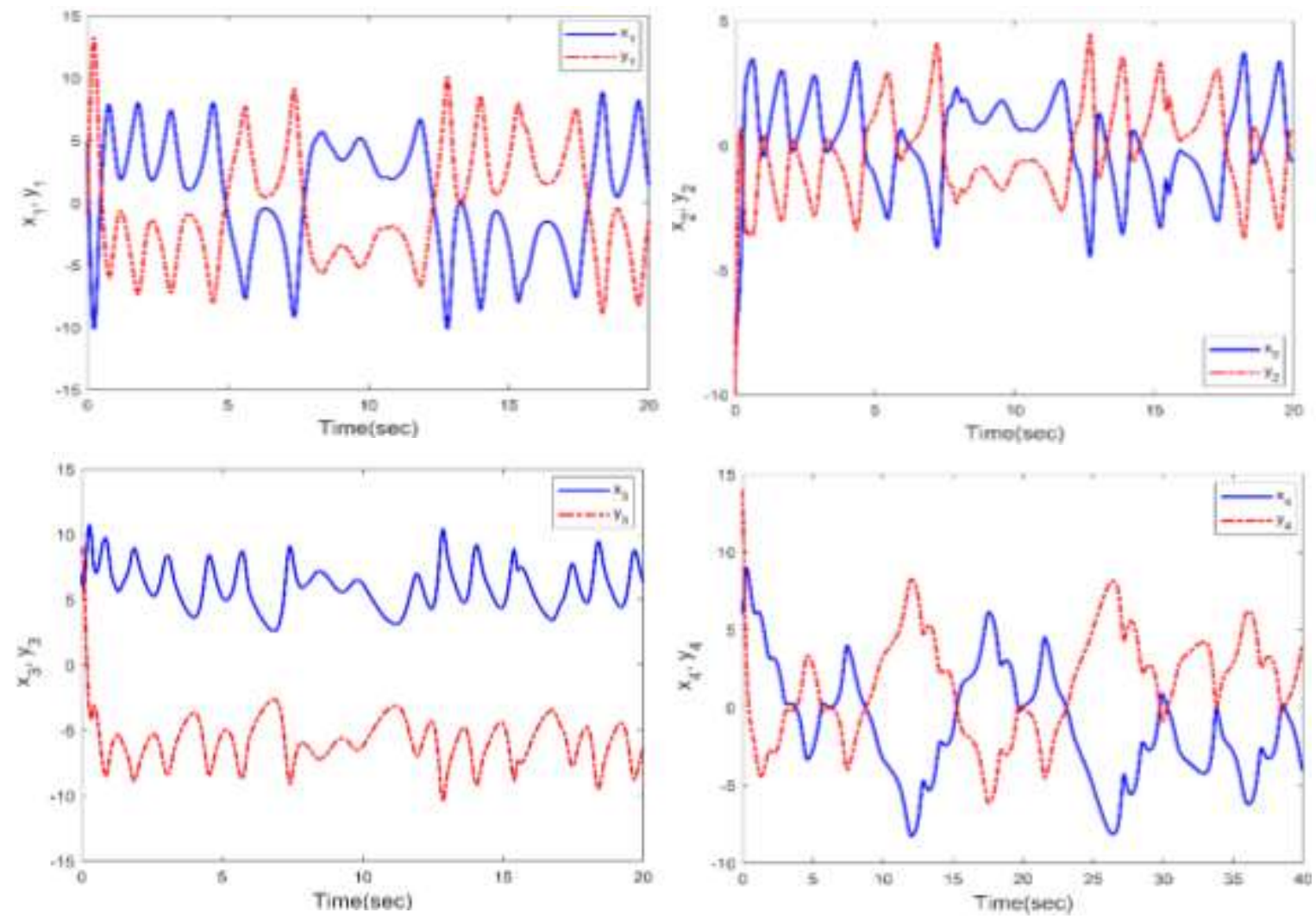

Figure 3. Anti-synchronization between systems (1) and (2) with control (8)

\subsection{Anti-Synchronization based on nonlinear control strategy}

In this section, anti-synchronization between system (1) and system (2) is considered by using another strategy which is called nonlinear control.

Theorem 2: The system (3) is stable, if design a controller consists of (12) terms as follows:

$$
\left\{\begin{array}{l}
u_{1}=2\left(x_{2} e_{3}-x_{2} x_{3}\right) \\
u_{2}=-2\left(\left(h-x_{3}\right) e_{1}+y_{1} x_{3}\right)+x_{1} e_{3} \\
u_{3}=-2\left(e_{1} e_{2}+x_{1} x_{2}\right)+y_{1} e_{2} \\
u_{4}=(k-1) e_{2}-e_{4}
\end{array}\right.
$$

Proof: With this choice, the error dynamical system (3) becomes 


$$
\left[\begin{array}{c}
\dot{e}_{1} \\
\dot{e}_{2} \\
\dot{e}_{3} \\
\dot{e}_{4}
\end{array}\right]=\left[\begin{array}{cccc}
-a & h-x_{3} & e_{2}+x_{2} & 0 \\
-h+x_{3} & -1 & -y_{1}+x_{1} & 1 \\
-e_{2}-x_{2} & -x_{1}+y_{1} & -1 & 0 \\
0 & -1 & 0 & -1
\end{array}\right]\left[\begin{array}{l}
e_{1} \\
e_{2} \\
e_{3} \\
e_{4}
\end{array}\right]
$$

i.e.

$$
\left\{\begin{array}{l}
\dot{e}_{1}=-a e_{1}+h e_{2}+e_{2} e_{3}-x_{3} e_{2}+x_{2} e_{3} \\
\dot{e}_{2}=-h e_{1}-e_{2}+e_{4}-y_{1} e_{3}+x_{3} e_{1}+x_{1} e_{3} \\
\dot{e}_{3}=-e_{3}-e_{1} e_{2}-x_{2} e_{1}-x_{1} e_{2}+y_{1} e_{2} \\
\dot{e}_{4}=-e_{2}-e_{4}
\end{array}\right.
$$

The Lyapunov function and it is derivative as (13) and (14) respectively:

$$
\begin{aligned}
& \mathrm{V}(\mathrm{e})=e^{T} p e \\
& \dot{V}(e)=-a e_{1}^{2}-e_{2}^{2}-e_{3}^{2}-e_{4}^{2}=-e^{T} Q e
\end{aligned}
$$

So $Q>0$. Therefore, $\dot{V}(e)$ is negative definite. The theorem 2 showed that proposed control which consists of (12) terms achieved anti-synchronization in Figure 4.
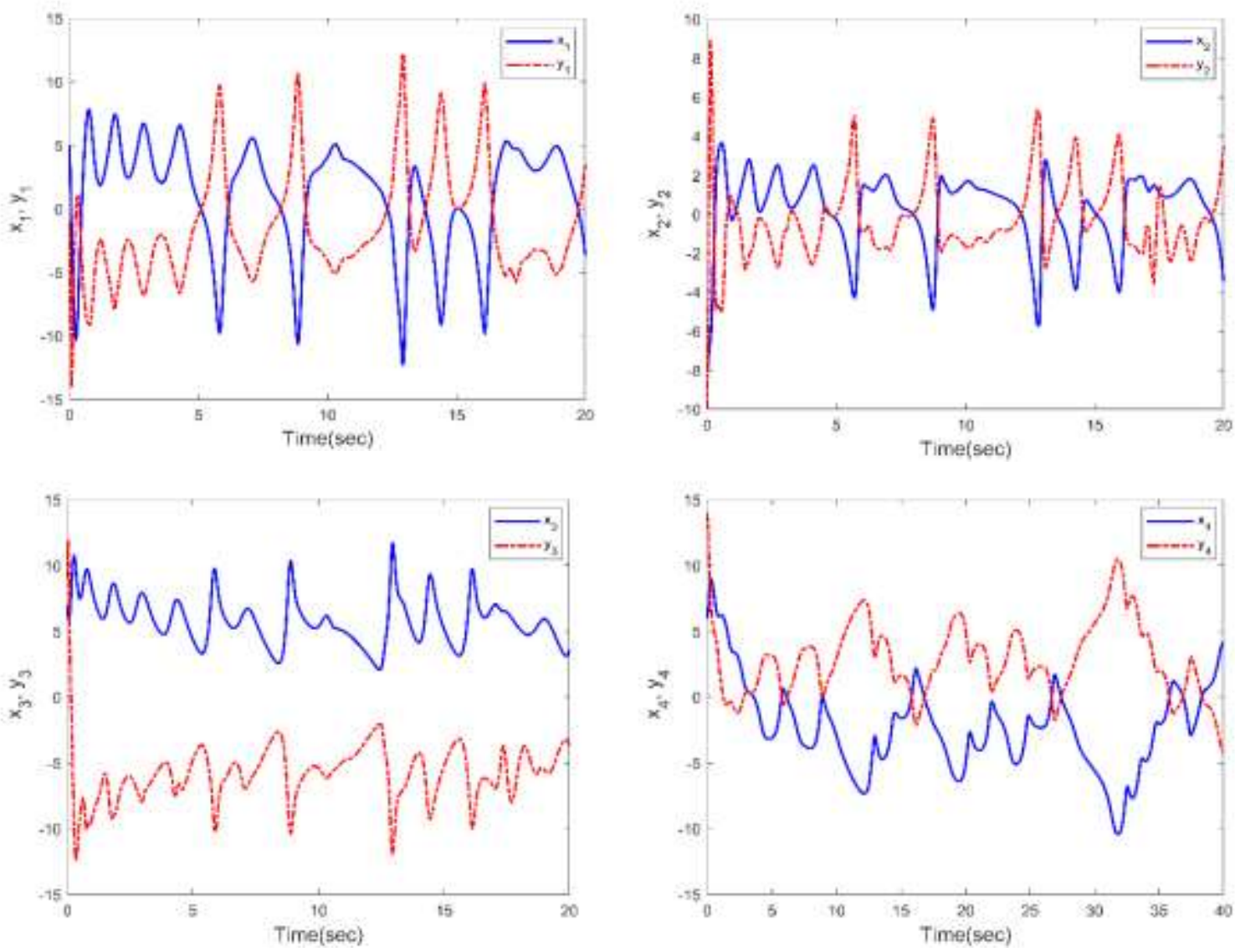

Figure 4. Anti-synchronization between systems (1) and (2) with control (11)

Theorem 3: If the controller is designed with (12) terms as follows:

$$
\left\{\begin{array}{l}
u_{1}=-2\left(h e_{2}+e_{2} e_{3}-x_{3} e_{2}+x_{2} x_{3}\right) \\
u_{2}=x_{1} e_{3}-e_{4}-2 y_{1} x_{3} \\
u_{3}=2\left(e_{1}-x_{1}\right) x_{2}+y_{1} e_{2} \\
u_{4}=k e_{2}-e_{4}
\end{array}\right.
$$


then, the response system (2) unfollow the drive system (1) via the following nonlinear control.

Proof: When substituting the controllers (15) in the system (3), we get:

$$
\left\{\begin{array}{l}
\dot{e}_{1}=-a e_{1}+\left(-h+x_{3}\right) e_{2}-\left(e_{2}+x_{2}\right) e_{3} \\
\dot{e}_{2}=\left(h-x_{3}\right) e_{1}-e_{2}+\left(-y_{1}+x_{1}\right) e_{3} \\
\dot{e}_{3}=\left(e_{2}+x_{2}\right) e_{1}+\left(-x_{1}+y_{1}\right) e_{2}-e_{3} \\
\dot{e}_{4}=-e_{4}
\end{array}\right.
$$

Construct Lyapunov function as:

$$
\mathrm{V}(\mathrm{e})=e^{T} p e=\frac{1}{2} e_{1}^{2}+\frac{1}{2} e_{2}^{2}+\frac{1}{2} e_{3}^{2}+\frac{1}{2} e_{4}^{2}
$$

Then

$$
\dot{V}(e)=-a e_{1}^{2}-e_{2}^{2}-e_{3}^{2}-e_{4}^{2}=-e^{T} Q e
$$

So, $\mathrm{V}(\mathrm{e})>0$ and $\dot{V}(e)<0$, the nonlinear controller is implemented. The theorem 3 showed that proposed control which consists of (12) terms achieved anti-synchronization in Figure 5.
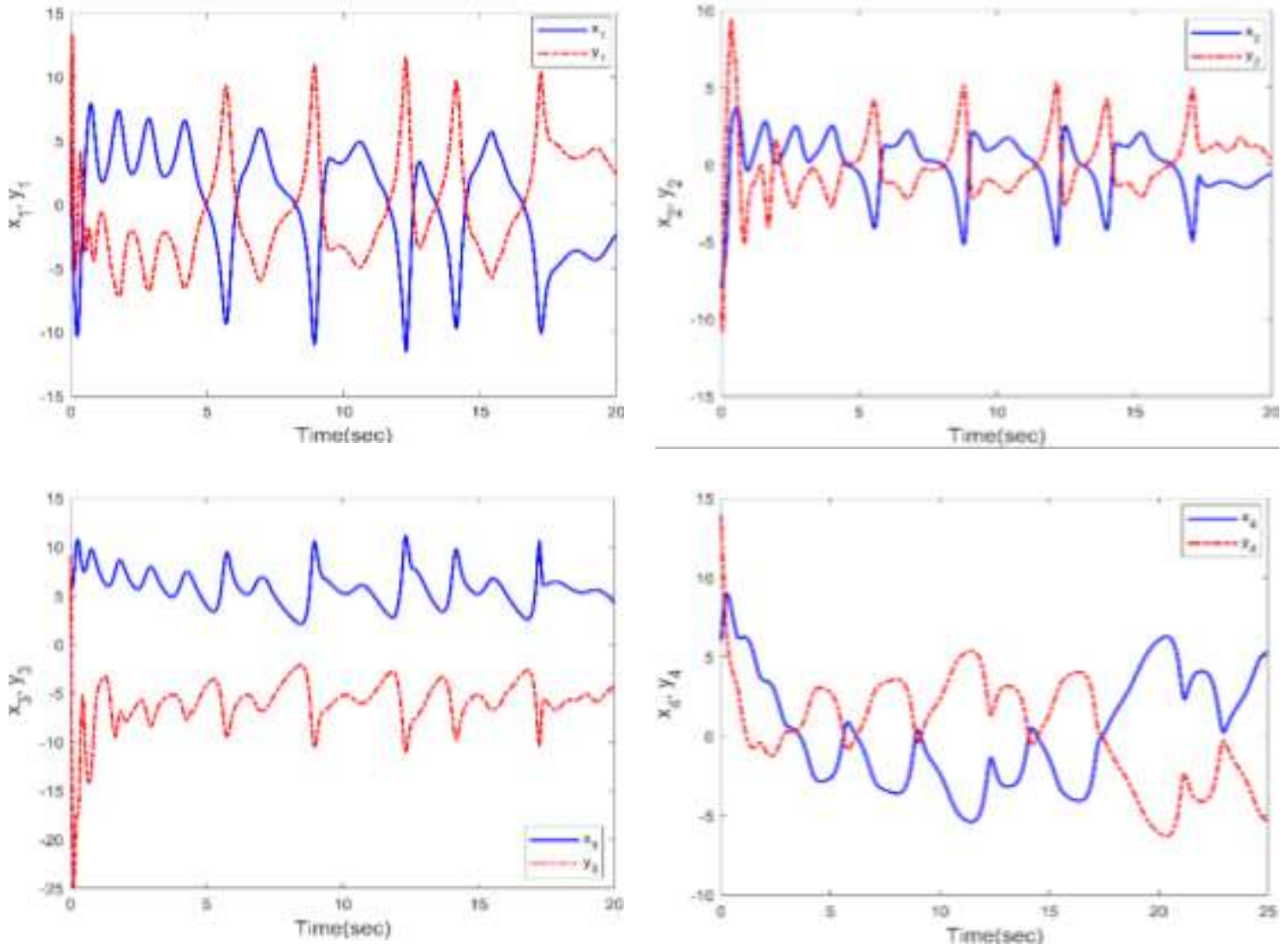

Figure 5. Anti- synchronization between systems (1) and (2) with control (15)

Theorem 4: The system (3) is achieved. If the controller is designed as:

$$
\left\{\begin{array}{l}
u_{1}=-2\left(x_{2}-e_{2}\right) x_{3} \\
u_{2}=-2 h e_{1}+y_{1} e_{3}-2 y_{1} x_{3} \\
u_{3}=-2\left(e_{2}-x_{2}\right) e_{1}+x_{1}\left(e_{2}-2 x_{2}\right) \\
u_{4}=(k-1) e_{2}-e_{4}
\end{array}\right.
$$


then, the response system (2) unfollows the drive system (1) via the following nonlinear control.

Proof: Using system (3) with the controller (17) is given by:

$$
\left\{\begin{array}{l}
\dot{e}_{1}=-a e_{1}+\left(h+x_{3}\right) e_{2}+\left(e_{2}-x_{2}\right) e_{3} \\
\dot{e}_{2}=-\left(h+x_{3}\right) e_{1}-e_{2}+e_{4} \\
\dot{e}_{3}=\left(x_{2}-e_{2}\right) e_{1}-e_{3} \\
\dot{e}_{4}=-e_{2}-e_{4}
\end{array}\right.
$$

The same results were found in theorem (3). The theorem 4 showed that proposed control which consists of (12) terms achieved anti-synchronization in Figure 6.
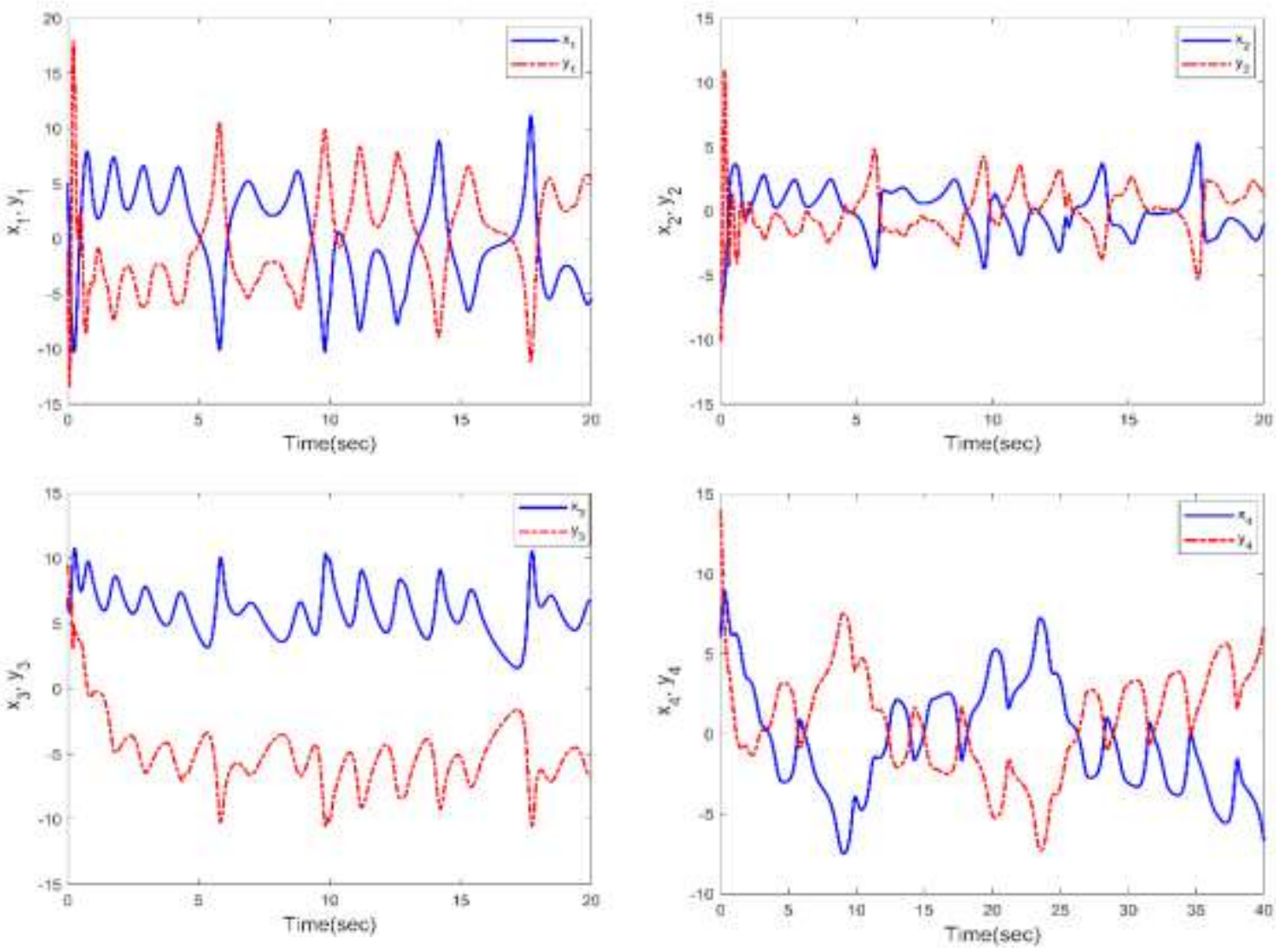

Figure 6. Anti-synchronization between systems (1) and (2) with control (17)

\section{CONCLUSION}

In the paper, the anti-synchronization problem for 4-D Rabinovich hyperchaotic system is considered, based on two strategies: active and non-linear controller. The stability of error dynamical systems are established based on the Lyapunov theory and compared between these strategies It was found that both of them lead to anti-synchronization, but the performance of the number of terms of the nonlinear controller is less than the active control.

\section{ACKNOWLEDGEMENTS}

The authors are very grateful to the University of Mosul/ College of Computer Sciences and Mathematics for their provided facilities, which helped to improve the quality of this work.

\section{REFERENCES}

[1] S. F. AL-Azzawi, "Stability and Bifurcation of Pan Chaotic System by Using Routh-Hurwitz and Gardan Method," Applied Mathematics and Computation, vol. 219, no. 3, pp. 1144-1152, October 2012. 
[2] A. Sambas, et al., "A New Chaotic System with Line of Equilibria: Dynamics, Passive Control and Circuit Design," International Journal of Electrical and Computer Engineering (IJECE), vol. 9, no. 4, pp. 2365-2376, August 2019.

[3] A.F., Qasim, B.J. Salim, "Application new iterative method for solving modified korteweg-de vries (MKdV) system from three equations," Journal of Advanced Research in Dynamical and Control Systems, vol.11, no. 3, pp. 20192026, August 2019.

[4] Z. N. Al-kateeb and M. R. Al-Bazaz, "Steganography in Colored Images Based on Biometrics," Tikrit Journal of Pure Science, vol. 24, no. 3, pp. 111-117, 2019.

[5] S. Mobayen, et al., "A Novel Chaotic System with Boomerang-Shaped Equilibrium, Its Circuit Implementation and Application to Sound Encryption," Iranian Journal of Science and Technology, Transactions of Electrical Engineering, vol. 43, pp. 1-12, 2019.

[6] A. Sambas, et al., "A New Chaotic System with a Pear-Shaped Equilibrium and Its Circuit Simulation," International Journal of Electrical and Computer Engineering (IJECE), vol. 8, no. 6, pp. 4951-4958, December 2018.

[7] S. Vaidyanathan, et al., "A New Chaotic System with Axe-Shaped Equilibrium, Its Circuit Implementation and Adaptive Synchronization," Archives of Control Sciences, vol. 28, no. 3, pp. 443- 462, January 2018.

[8] A. S. Al-Obeidi and S. F. AL-Azzawi, "Complete Synchronization of a Novel 6-D hyperchaotic Lorenz System with Known Parameters," International Journal of Engineering \& Technology, vol. 7, no. 4, pp. 5345-5349, 2018.

[9] A. S. Al-Obeidi and S. F. AL-Azzawi, "Chaos Synchronization of a Class 6-D Hyperchaotic Lorenz System," Modelling, Measurement and Control B, vol. 88, no. 1, pp.17-22, March 2019.

[10] H. K. Chen, "Global Chaos Synchronization of New Chaotic Systems via Nonlinear Control," Chaos, Solitons and Fractals, vol. 23, no. 4, pp. 1245-1251, February 2005.

[11] S. F. AL-Azzawi and M. M. Aziz, "Chaos Synchronization of Nonlinear Dynamical Systems via a Novel Analytical Approach," Alexandria Engineering Journal, vol. 57, no. 4, pp. 3493-3500, December 2018.

[12] M. M. Aziz and S. F. AL-Azzawi," Anti-Synchronization of Nonlinear Dynamical Systems Based on Cardano's Method," Optik, vol. 134, pp. 109-120, January 2017.

[13] M. M. Aziz and S. F. AL-Azzawi," Hybrid Chaos Synchronization Between Two Different Hyperchaotic Systems via Two Approaches," Optik, vol. 138, pp. 328-340, June 2017.

[14] A. S. Al-Obeidi and S. F. AL-Azzawi, "Projective Synchronization for a Class of 6-D Hyperchaotic Lorenz System," Indonesian Journal of Electrical Engineering and Computer Science (IJEECS), vol. 16, no.2, pp. 692-700, November 2019.

[15] G. H. Li, "Modified Projective Synchronization of Chaotic System," Chaos, Solitons \& Fractals, vol. 32, no. 5, pp. 1786-1790, June 2007.

[16] C. Li and J. Yan, "Generalized Projective Synchronization of Chaos: The Cascade Synchronization Approach," Chaos, Solitons \& Fractals, vol. 30, no. 1, pp. 140-164, October 2006.

[17] M. T. Yassen, "Chaos Synchronization Between Two Different Chaotic Systems Using Active Control," Chaos, Solitons \& Fractals, vol. 23, no.1, pp. 131-140, January 2005.

[18] A. S. Al-Obeidi and S. F. AL-Azzawi, "Chaos Synchronization in a 6-D Hyperchaotic System with Self-Excited Attractor," Telkomnika, vol. 18, 2020.

[19] J. H. Park, "Chaos Synchronization of a Chaotic System via Nonlinear control," Chaos Solitons Fractals, vol. 25, no.3, pp. 579-584, August 2005.

[20] G. Cai and Z. Tan, "Chaos Synchronization of a New Chaotic System via Nonlinear control," Journal of Uncertain Systems, vol. 1, pp. 235-240, 2007.

[21] A. S. Al-Obeidi and S. F. AL-Azzawi, "A Novel Six-Dimensional Hyperchaotic System with a Self-Excited Attractors and Its Chaos Synchronization," International Journal of Computing Science and Mathematics.

[22] M. T. Yassen, "Controlling Chaos and Synchronization for New Chaotic System Using Linear Feedback Control," Chaos Solitons Fractals, vol. 26, no. 3, pp. 913-920, November 2005.

[23] S. F. AL-Azzawi and M. M. Aziz, "Strategies of Linear Feedback Control and Its Classification," TELKOMNIKA, vol. 17, no. 4, pp. 1931-1940, August 2019.

[24] M. M. Aziz., S. F. AL-Azzawi, "Some Problems of Feedback Control Strategies and its Treatment," Journal of Mathematics Research, vol. 9, no.1, pp. 39-49, February 2017.

[25] A. Ouannas, et al., "Synchronization of Fractional Hyperchaotic Rabinovich Systems via Linear and Nonlinear Control with an Application to Secure Communications," International Journal of Control, Automation and Systems, vol. 17, pp. 2211-2219, 2019.

[26] J. M. He and F. Q. Chen," A new Fractional Order Hyperchaotic Rabinovich System and Its Dynamical Behaviors," International Journal of Non-Linear Mechanics, vol. 97, pp. 73-81, October 2017. 